\title{
Effect and Tolerability of the Combined Plant Extract (PAC) in Treatment of Acne Vulgaris
}

\author{
Haesun Park', Sujung Woo', Jinsook Hyun', Hyeonji Kim², Jiyoung You², Hyunju Woo², \\ Eunsun Jung'2, Kwangseon Jung1, Myungok Kim ${ }^{1}$
}

\author{
${ }^{1}$ Skincure Life Science Institute, Jeju, Korea \\ ${ }^{2}$ Biospectrum Life Science Institute, Yongin, Korea \\ Email: jeju04@skin arre.co.kr
}

How to cite this paper: Park, H., Woo, S., Hyun, J., Kim, H., You, J., Woo, H., Jung, E., Jung, K. and Kim, M. (2018) Effect and Tolerability of the Combined Plant Extract (PAC) in Treatment of Acne Vulgaris. Journal of Cosmetics, Dermatological Sciences and Applications, 8, 55-72.

https://doi.org/10.4236/jcdsa.2018.82009

Received: April 10, 2018

Accepted: June 18, 2018

Published: June 21, 2018

Copyright $\odot 2018$ by authors and Scientific Research Publishing Inc. This work is licensed under the Creative Commons Attribution International License (CC BY 4.0).

http://creativecommons.org/licenses/by/4.0/

\begin{abstract}
This study was undertaken to identify a new combined plant extract (PAC) intended to treat in patients with acne vulgaris. We detected strong antibacterial activities of Pinus densiflora leaf extract (LP) against Propionibacterium acnes ( $P$. acnes) and Staphylococcus epidermidis ( $S$. epidermidis) and anti-inflammatory effect of Artemisia annua L. extract (AA). To develop more effective agents in multiple targeting of the physiopathology of acne, a combination of three plant extracts (PAC), Pinus densiflora leaf extract (LP), Artemisia annua L. extract (AA), and Citrus junos fruit juice (FC), indicated anti-proliferative effect on $P$. acnes-induced $\mathrm{HaCaT}$ cells proliferation, was prepared mixing at ratio 2:1:1. PAC with MIC values of $2.25 \mathrm{mg} / \mathrm{ml}$ and 0.75 $\mathrm{mg} / \mathrm{ml}$ against $P$. acnes and $S$. epidermidis was more active than LP $(2.50$ $\mathrm{mg} / \mathrm{ml}$ and $1.00 \mathrm{mg} / \mathrm{ml}$ ), was the most active of three extracts. PAC also showed more effective anti-inflammatory activity than a single plant extract in $P$. acnes-treated NF, HaCaT cells and LPS-treated Raw 264.7 cells. And then, we evaluated sebosuppressive effect of PAC on differentiation and lipogenesis of sebocytes. Results showed that PAC reduced sebum production and IGF-1-stimulated proliferation on sebocytes. In addition, PAC (final 2\%) applied in a test product clinically decreased skin oil content, sebum output lev$\mathrm{el}$, and the number of closed comedones and open comedones in a period of 4 weeks. The results of the studies demonstrate that PAC is clinically effective with anti-bacterial, anti-inflammatory, sebum protective properties for acne prone skin. These results suggest that in patients with acne, PAC can provide adjunctive care by targeting pathological factors including bacterial proliferation, inflammation and sebum production.
\end{abstract}

\section{Keywords}

Anti-Microbial Activity, Acne, Anti-Inflammatory, Clinical Study, Sebum 


\section{Introduction}

Acne vulgaris is a multifactorial skin disease, and its pathogenesis includes increased sebum production (seborrhea), hyperkeratosis, proliferation of Propionibacterium acnes ( $P$. acnes) and inflammation [1] [2] [3].

In particular, sebum overproduction is a major concurrent event in the development of acne lesions [4] [5] because sebum serves as a nutrient source for $P$. acnes, activating toll-like receptors TLR2 and TLR4, leading to the release of proinflammatory cytokines/chemokines such as interleukin-1 $\alpha$ (IL- $1 \alpha$ ), IL-6, IL-8, tumor necrosis factor- $\alpha$ (TNF- $\alpha$ ), and adhesion molecule like intercellular adhesion molecule-1 (ICAM-1) [6] [7] [8]. It can also promote hyperkeratinization, resulting from abnormal keratinization of infundibular epithelium [9]. Therefore, acne treatment relies on developing new drugs that regulate sebum excretion centers [10] [11].

Sebum is a lipid-rich fluid that is, secreted by the sebaceous gland, and it is composed of cholesterol, fatty acids, fatty alcohols, di- and tri-glycerides, wax esters, sterol esters and squalene [12] [13] [14]. It has long been known that sebum excretion in sebocytes is regulated by androgens and androgen-mediated stimulation of the sebaceous gland changes sebum composition [15] [16] [17] [18]. Moreover, subsequent excess in sebum production of androgen-stimulated sebocytes and follicular keratinocytes causes hyperkeratosis, which results in blockage of the follicle in sebaceous glands and aggravates acne vulgaris. In normal hair follicles, keratinocytes are carried by sebum flow to the skin surface, but these are densely packed, and their proliferation rate increases in an acne lesion [19] [20].

Recent evidence suggests that IGF-1 levels increase in people with clinical acne and IGF-1 or insulin, which can stimulate sebaceous gland lipogenesis in rat sebocytes [21] [22] [23]. Thus, studies are increasingly carried out to target the suppression of IGF-1-induced lipogenesis in sebocytes. Epigallocatechin-3-Gallate (EGCG), the major polyphenol in green tea, suppresses sebum production on IGF-1-stimulated SZ95 sebocytes by inhibiting PI3K-Akt-mTORC1 (Phosphoinositide 3-kinase-Akt-mammalian target of rapamycin complex 1) signaling [24] [25].

Due to the pathophysiology of acne caused by the increase in sebum secretion, hyperkeratosis, growth of $P$. acnes, and inflammation, there are limits to developing safe, effective therapeutics for acne. Even the most effective treatments require several months to produce noticeable effects since therapeutic agents that are currently available to treat acne target different physiological aspects, such as killing bacteria, preventing inflammation or suppressing comedo production.

Therefore, developing novel agents for acne, by targeting a diverse range of pathological factors is of particular importance, and there has been an increase in interest for multifunctional ingredients, indicating antibacterial activity, anti-inflammation, sebo-suppressive effect, and hyperkeratosis. 
Pinus thunbergii is a tree species that is extensively planted along coastal regions in Korea, China, and Japan. This species is demanding since it is salt-tolerant, stabilize dunes, and provides a wind-break effect [26] [27] [28]. Pinus thunbergii extracts have been shown to have antiviral activity against influenza virus $\mathrm{A} / \mathrm{PR} / 8 / 34$ and, inhibitory effects on antigen-induced degranulation in RBL-2H3 cells [29] [30]. Currently, there has been little to no study of the bioactivity of Pinus thunbergii, and in the study, we have thus evaluated the activity of Pinus thunbergii leaf extracts in treating acne.

Artemisia annua L., belongs to the Asteraceae family and, is one of the most widely used herbs in oriental medicine. It is also well known as the source of sesquiterpene lactone artemisinin, which is used to treat chloroquine-resistant and cerebral malaria [31] [32] [33]. Artemisia annua L. and artemisinin have been extensively studied for anti-inflammatory, antipyresis, antibacterial, antiparasitice, and immunosuppressive effects [34] [35] [36] [37]. Despite numerous studies with Artemisia annua L., its effect on acne has not been studied. In this study, we investigated the anti-inflammatory activity against $P$. acne-induced inflammation and anti-acne activity of the PAC complex-containing Artemisia annua L. extract.

Also, Citrus junos Tanaka (yuza), a yellow-coloured citrus fruit similar to a kind of sour orange, has traditionally been used in Korea, Japan, and China. It has been reported to exhibit antidiabetic, anticancer, antioxidative, and anti-inflammatory effects as well as inhibiting hepatic lipid accumulation [38] [39] [40] [41]. In addition, many cosmetics and perfume producers use the essential oil of Citrus junos Tanaka to manufacture their products because of its distinctive, pleasing fragrance [42]. Little is known about the inflammation and anti-acne activity of Citrus junos Tanaka, so we examined its pharmacological effects to expand on its usage in herbal medications.

The present study reports the results of in vitro, ex vivo, and clinical studies conducted with natural combined plant extract (PAC), consisting of Pinus thunbergii leaf extract (LP), Artemisia annua L. extract (AA), and Citrus junos Tanaka fruit juice (FC) to assess the antibacterial, anti-inflammatory, sebum protective, and clinical efficacy on acne lesions. This study suggests that PAC can improve treatment and provide complete adjunctive care in patients with acne.

\section{Methods}

\subsection{Materials}

Dulbecco's-Modified Eagle's Medium (DMEM), antibiotics, fetal bovine serum (FBS) and phosphate-buffered saline (PBS) and trypsin were purchased from Gibco (USA). Lipopolysaccharides (LPS) and Griess reagent were obtained from Sigma Aldrich (St. Louis, MO, USA).

\subsection{Preparation of Extracts}

Leaves of Pinus thunbergii, Artemisia annua L., and fruits of Citrus junos Tana- 
ka were harvested in Jeju-do, Korea, from June to August and were authenticated by Dr. Yong-Hwan Jung, Jeju Biodiversity Research Institute, Jeju TechnoPark, Korea, where a voucher specimen remains (Voucher No JBRI 140924-01). The dried leaves of Pinus thunbergii (150 g) or the whole plant (150 g) of Artemisia annua L. was extracted with $300 \mathrm{ml}$ of $70 \%$ ethanol for $24 \mathrm{~h}$ at room temperature. And each extracted solution was subsequently filtered using a filter paper and then evaporated to remove the ethanol by a rotary evaporator for $3 \mathrm{~h}$. Two extracts were frozen on a freezing tray for $48 \mathrm{~h}$ and lyophilized. 16.0 $\mathrm{g}$ of Pinus thunbergii leaf extract (LP) and $27.4 \mathrm{~g}$ of Artemisia annua L. extract (AA) were harvested. FC was obtained by stirring the fruits of Citrus junos Tanaka using an industrial blender and passing the resulting mixture through a strainer to remove seeds and peels. FC juice was then clarified by centrifugation at $10,000 \mathrm{rpm}$ for $30 \mathrm{~min}$ at $4^{\circ} \mathrm{C}$. LP, AA, and FC were mixed at the ratio of 2:1:1, respectively to obtain the mixture preparation, PAC.

\subsection{Bacterial Culture}

$P$. acnes strain (ATCC 11827) and S. epidermidis (ATCC 12228) were obtained from the Korean Collection for Type Cultures (KCTC, Korea). P. acnes was cultured in BHI (brain heart infusion) broth medium for $24 \mathrm{~h}$ at $37^{\circ} \mathrm{C}$ under anaerobic conditions. S. epidermidis was cultured in nutrient broth (NB) in aerobic conditions at $37^{\circ} \mathrm{C}$ for $24 \mathrm{~h}$.

\subsection{Cell Culture}

The Normal human adult dermal fibroblasts NF (ATCC PCS-201-012), Murine macrophage cell line Raw 264.7 (ATCC TIB-71), immortalized human sebocyte cell line SEB-1 were purchased from Americal Type Culture Collection (ATCC). The human keratinocyte cell line $\mathrm{HaCaT}$ was obtained from the Korea Cell Line Bank (Seoul, Korea). NF, HaCaT and Raw 264.7 cells were cultured in DMEM, supplemented with $10 \%$ FBS and $1 \%$ antibiotics (penicillin 100 units $/ \mathrm{ml}$ and streptomycin $100 \mathrm{ug} / \mathrm{ml}$ ). The cells were maintained in a humidified atmosphere with $5 \% \mathrm{CO}_{2}$ at $37^{\circ} \mathrm{C}$. SEB-1 cell line was grown in standard culture medium consisting of DMEM, 5.5 mM glucose/Ham's F-12 3:1, 2.5\% FBS, adenine $1.8 \times$ $10^{-4} \mathrm{M}$, hydrocortisone $0.4 \mathrm{ug} / \mathrm{ml}$, insulin $10 \mathrm{ng} / \mathrm{ml}$, epidermal growth factor 3 $\mathrm{ng} / \mathrm{ml}$, and cholera toxin $1.2 \times 10^{-10} \mathrm{M}$ (Thiboutot et al., 2003).

\subsection{Minimum Inhibitory Concentration (MIC) Test}

Bacteria were pre-cultured anaerobically for $24 \mathrm{~h}$ at $37^{\circ} \mathrm{C}$. About $1 \times 10^{4}$ cells from the pre-culture were seeded into $3 \mathrm{ml}$ of broth medium and were cultured until their exponential phase had been reached. Subsequently, the extracts were treated into the culture broth. After bacterial incubation at $37^{\circ} \mathrm{C}$ under anaerobic conditions for $24 \mathrm{~h}$, the MIC of the extracts were determined using a two-fold serial dilution method. The lowest concentration yielding no bacterial growth was regarded as the MIC value. 


\subsection{Griess Assay}

The Raw 264.7 cells were seeded at $1 \times 10^{5}$ cells/well into a 24 well-tissue culture plate and incubated overnight. The cells were pretreated with LP, AA, FC, and PAC for $1 \mathrm{~h}$ and were further incubated with LPS $(200 \mathrm{ng} / \mathrm{ml})$ for $24 \mathrm{~h}$ at $37^{\circ} \mathrm{C}$. Then, the amount of NO production was measured by performing a Griess assay [43]. The culture supernatants were incubated with Griess reagent $(0.1 \%$ $\mathrm{N}$-1-naphthylenediamine digydrochloride and $1 \%$ sulphanilamide in 5\% phosphoric acid) for $30 \mathrm{~min}$ at RT. The absorbance at $570 \mathrm{~nm}$ was measured using a spectrometer, and the nitrate concentration was calculated from a $\mathrm{NaNO}_{2}$ standard curve.

\subsection{IL-8 ELISA Assay}

The NF cells $\left(5 \times 10^{3}\right.$ cells/well $)$ in serum-free medium were pretreated with LP, AA, FC, and PAC for $1 \mathrm{~h}$ and stimulated with $P$. acnes $(1: 1000)$ for $48 \mathrm{~h}$ at $37^{\circ} \mathrm{C}$. Then, the culture supernatants were harvested for IL-8. The IL-8 concentration resulting from its production was measured by using a commercially available ELISA kit (eBioscience, USA), and the absorbance at $405 \mathrm{~nm}$ was measured using a spectrometer. The IL- 8 concentration was determined using a standard curve.

\subsection{Cell Viability Assay}

The Raw264.7, NF, and HaCaT cells assayed in terms of viability using 3-[4,5-dimethylthiazol-2-yl]-2,5 diphenyltetrazolium bromide (MTT), which is reduced to purple formazan in living cells. The cells were plated in triplicate wells of 24 well-tissue culture plates and were incubated for $24 \mathrm{~h}$. The cells were then exposed to LP, AA, FC, and PAC for $24 \mathrm{~h}$ at $37^{\circ} \mathrm{C}$. The MTT solution (1 $\mathrm{mg} / \mathrm{ml}$ ) was then added to each well and was cultured for $2 \mathrm{~h}$. Subsequently, the supernatant was removed, and the insoluble purple formazan was dissolved in dimethyl sulfoxide (DMSO, St. Louis, MO, USA). The absorbance at $540 \mathrm{~nm}$ was measured using a spectrophotometer.

\subsection{Cell Cycle Analysis}

To measure the cell cycle progression, a flow cytometric analysis was performed with propidium iodide (PI). The SEB-1 sebocytes were treated with $1 \mathrm{ug} / \mathrm{ml}$ PAC or $1 \mathrm{uM}$ EGCG treatments and then, the cells were stimulated with $20 \mathrm{nM}$ of IGF-1 in DMEM without serum for $24 \mathrm{~h}$. After that, the cells were pelleted, washed with ice-cold phosphate-buffered saline, and fixed with $70 \%$ ice-cold ethanol for $1 \mathrm{~h}$. For the cell cycle analysis, ethanol-fixed cells were washed with PBS and, resuspended in Rnase A solution $(0.5 \mathrm{mg} / \mathrm{ml})$ in PBS. After $1 \mathrm{~h}$ of incubation, the cellular DNA was stained with $50 \mathrm{ug} / \mathrm{ml}$ PI solution in the dark for $20 \mathrm{~min}$ at $4^{\circ} \mathrm{C}$. The relative DNA concentration of the stained cells was analyzed using a FACS Calibur flow cytometer (Becton Dickinson, San Jose, CA, USA). 


\subsection{Nile Red Staining}

The SEB-1 sebocytes were treated with $20 \mathrm{nM}$ of IGF- 1 with $1 \mathrm{ug} / \mathrm{ml} \mathrm{PAC}$ or 1 uM EGCG treatments for $24 \mathrm{~h}$. The cells were harvested and washed with phosphate-buffered saline without $\mathrm{Ca}^{2+}$ and $\mathrm{Mg}^{2+}$. The harvested cells were fixed with $4 \%$ paraformaldehyde for $15 \mathrm{~min}$, and then stained with $1 \mathrm{ug} / \mathrm{ml} \mathrm{Nile} \mathrm{red} \mathrm{(Sig-}$ $\mathrm{ma}$, St Louis, MO) solution for 5 min while protected from light at $37^{\circ} \mathrm{C}$. An observation was realized using a fluorescence microscope with appropriate filters.

\subsection{Clinical Study}

The efficacy and tolerability of PAC-containing test product in treating facial acne has also been clinically validated. PAC-containing test product and a control product were formulated as shown in Table 1. For the 4-week, double-blinded study, twenty healthy volunteers aged 19 to 43 years (average age: 29.1, gender: female) were selected and were provided a consent form after being informed of the object and all related content. The subjects applied PAC-containing test product on their left side of face and a control product on their right side of face twice a day for 4 weeks. Prior to each test, the subjects washed their face. Skin oil content, sebum number, the numbers of acne lesions were estimated 3 times at 0,2 , and 4 weeks. Skin oil content was measured by Sebumeter ${ }^{\circledR}$ CM825 (C + K, Germany) and the measurement is based on grease spot photometry. Sebum number was measured by ECOSkin ${ }^{\circledR}$ (Cuvitz, Korea), which is based on the energy band diagram of fluorescence from skin. Lesions were recorded for the whole face (excluding the nose and jaw) by individually counting the number of whiteheads, blackheads, papules and pustules. The rate of the mean variation value was defined using the following formula:

$$
\Delta \%=\left[\left(T t_{i}-T t_{0}\right) / T t_{0}\right] \times 100
$$

with $T t_{i}=$ measured on the treated zone at time $t i$ and $T t_{0}=$ measured on the treated zone at time $t_{0}$. Student's t-test was used to compare the variations at

Table 1. Formulation of PAC-containing test product.

\begin{tabular}{cccc}
\hline Phase & INCI name & Control product (\%) & Test product (\%) \\
\hline \multirow{2}{*}{ A } & Deionized water & To 100 & To 100 \\
& Glycerin & 2.00 & 2.00 \\
A-1 & Xanthan Gum & 0.34 & 0.34 \\
& Sodium hyaluronate & 0.05 & 0.05 \\
& Deionized water & 10.00 & 10.00 \\
B & Polysorbate & 0.5 & 0.50 \\
& Propanediol & 2.00 & 2.00 \\
C & PAC & - & 2.00 \\
& 1,2-hexanediol & 2.00 & 2.00 \\
D & Caprylyl glycol & 0.05 & 0.05 \\
& Cthylhexylycerin & 0.20 & 0.20 \\
\hline
\end{tabular}

a. Sample of a Table footnote ( Table footnote is dispensable). 
different study visits compared to day 0 and between compounds. This clinical study was performed in accordance with the Declaration of Helsinki (2000) and was approved by the Ethics Committee of the DERMAPRO/Skin Research Center.

\subsection{Human Skin Primary Irritation Test}

A patch test was performed to evaluate the irritation potential of PAC on human skin. The subject group included 31 healthy females who had no history of allergenic contact dermatitis, and the average age of subjects was $41.6 \pm 6.5 \mathrm{yrs}$ (ranged 20 - 50). The PAC (2\%) formulated with squalene was prepared and applied to healthy skin on the back. The patch test system was usually removed after 48 hours. Once the patches were removed, a reading was performed after 48 and $72 \mathrm{~h}$. The readings were rated according to the modification of Frosch and Kligman [44] as well as the Cosmetic, Toiletry and Fragrance Association (CTFA) guidelines as follows: $0=$ no reaction; $1=$ slight erythema, spotty of diffuse; 2 = moderate uniform erythema; 3 = intense erythema with oedema: $4=$ intense erythema with oedema and vesicles. The subjects were instructed to keep the test sites dry during the application period. This study was approved by the ethics committee of the DERMAPRO/Skin Research Center.

\subsection{Statistical Analysis}

Statistical significance of the data was analysed using one-way ANOVA analysis and Student's $t$-test. All experiments were repeated at least three times. A $P$ value $<0.05$ was considered to be significant.

\section{Results}

\subsection{Anti-Bacterial Effect of LP, AA, and PAC against $P$. acnes and $S$. epidermidis}

The anti-bacterial activity of LP, AA, FC, and PAC against $P$. acnes and $S$. epidermidis was investigated by measuring the minimum inhibitory concentration (MIC). The MIC was determined using a two-fold serial dilution (Table 2). Then, tetracyclin and erythromycin were employed as positive controls. LP, AA, and PAC were founded to have significant inhibitory effects against both bacteria. Among three tested single extracts, LP exhibited the strongest activity with MIC values of $1 \mathrm{mg} / \mathrm{ml}$ and $2.5 \mathrm{mg} / \mathrm{ml}$ against $S$. epidermidis and $P$. acnes, respectivly. However, PAC inhibited the growth of $S$. epidermidis and $P$. acnes at the lower concentration of $0.75 \mathrm{mg} / \mathrm{ml}$ and $2.25 \mathrm{mg} / \mathrm{ml}$, although its activity was less potent than those of tetracyclin and erythromycin. The results showed that PAC has stronger anti-bacterial ability than a single extract against $S$. epidermidis and $P$. acnes.

\subsection{Anti-Inflammatory Effect of LP, AA, and PAC on P. acnes or LPS-Induced Inflammation}

The increase in the inflammatory response within the pilosebaceous unit through bacteria colonization of the follicule is another critical pathological 
Table 2. MIC of LP, AA, FC, and PAC against $P$. acnes amd $S$. epidermidis.

\begin{tabular}{ccccccc}
\hline & \multicolumn{5}{c}{$\mathrm{MIC}^{\mathrm{a}}(\mathrm{mg} / \mathrm{ml})$} \\
\cline { 2 - 7 } Microorganism & LP & AA & FC & PAC & Tetracycline & Erythromycin \\
\hline P. acnes & 2.50 & 9.00 & - & 2.25 & 0.01 & 0.01 \\
S. epidermidis & 1.00 & 5.75 & - & 0.75 & 0.25 & 0.01 \\
\hline
\end{tabular}

a. MIC, Minimum Inhibitory Concentration.

factor for acne [45] [46]. Therefore, we evaluated whether LP, AA, FC, and PAC has an anti-inflammatory effect on $P$. acnes-induced IL-8 secretion in NF and HaCaT cells. LP and AA protected IL-8 production at $83.5 \%$ and $50.7 \%$ at the 20 ppm in NF cells. PAC exhibited significant IL-8 inhibition activity of $94.1 \%$, after treatment with PAC of $20 \mathrm{ppm}$, compared to the $P$. acnes-treated group (Figure 1(a)). In the case of the HaCaT cells, LP and FC showed IL-8 production $67.2 \%$ and $6.5 \%$ inhibition at $20 \mathrm{ppm}$. PAC inhibited $95.8 \%$ at $20 \mathrm{ppm}$ on $P$. acnes-induced IL-8 release in HaCaT cells (Figure 1(c)). In addition, the inhibitory effect against LPS-stimulated NO production in Raw 264.7 cells were investigated. The results indicated that $\mathrm{LP}$ and $\mathrm{AA}$ inhibited NO release at $28.1 \%$ and $22.8 \%$ at $50 \mathrm{ppm}$ and PAC indicated an inhibitory activity of $72.8 \%$ at 20 ppm, respectively (Figure 2). These results showed that PAC exerts the highest anti-inflammatory activity against bacteria-induced inflammation on acne lesions, as compared to tested single crude extract.

\subsection{Anti-Proliferative Effects of FC and PAC on Human Keratinocytes}

As shown in Figure 1(d), FC and PAC showed inhibitory effects on $P$. acnes-induced HaCaT cells and no cytotoxic effect was observed on Raw 264.7 and NF cells (except $40 \mathrm{ppm}$ of PAC). Abnormal human keratinocytes on hyperkeratosis are densely packed in the sebaceous gland and their proliferation rate increases in an acne lesion. The cytotoxic effects of FC on $P$. acnes-stimulated $\mathrm{HaCaT}$ cells indicated sensitivity for $\mathrm{FC}$ on the growth of $\mathrm{Ha}$ CaT cells. Also, PAC, including FC inhibits $\mathrm{HaCaT}$ cell proliferation and the viability of FC- and PAC- treated $\mathrm{HaCaT}$ cells were reduced dose-dependently. These results exhibited PAC has inhibitory effect on $P$. acnes-mediated HaCaT cells proliferation.

\subsection{Protective Effect of PAC on Sebocyte Differtiation}

An excess in sebum production is a major concurrent event associated with the pathogenesis of acne. To identify whether PAC has a sebosuppressive effect, we examined the effect of PAC on lipid production and proliferation in human sebocytes. Recent studies have shown that elevated insulin/insulin-like growth factor-1 (IGF-1) signaling stimulates the androgen metabolism of sebocytes and the lipogenesis of sebaceous glands [21] [23]. We investigated the effect of PAC on sebocyte proliferation and lipid production in IGF-1-stimualted SEB-1 cells. 


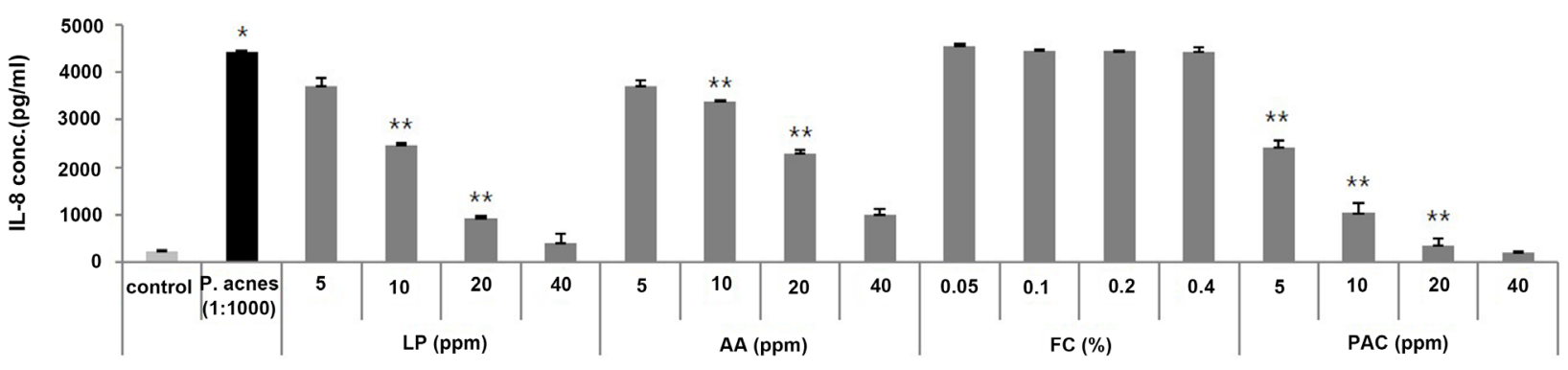

(a)

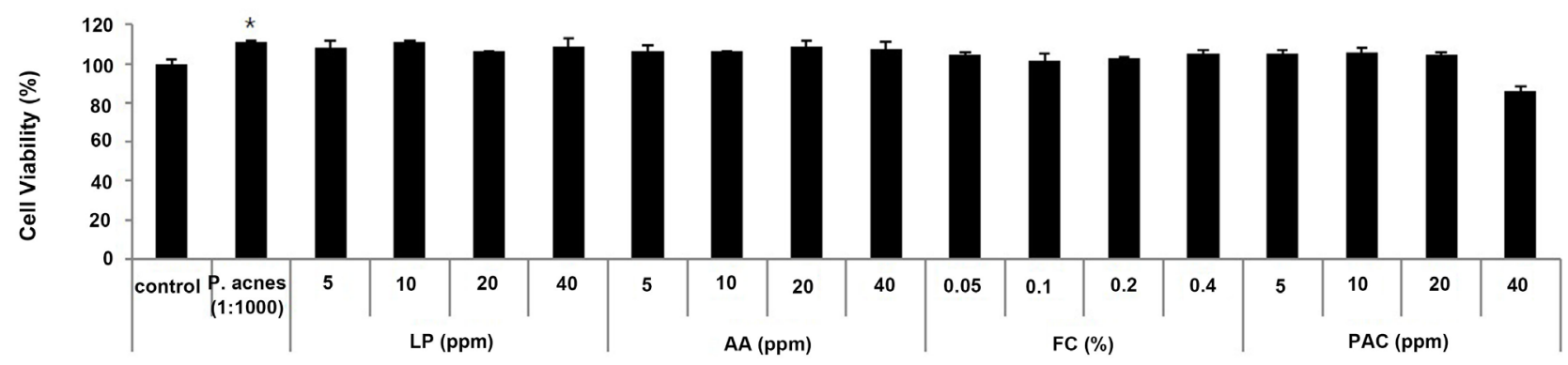

(b)

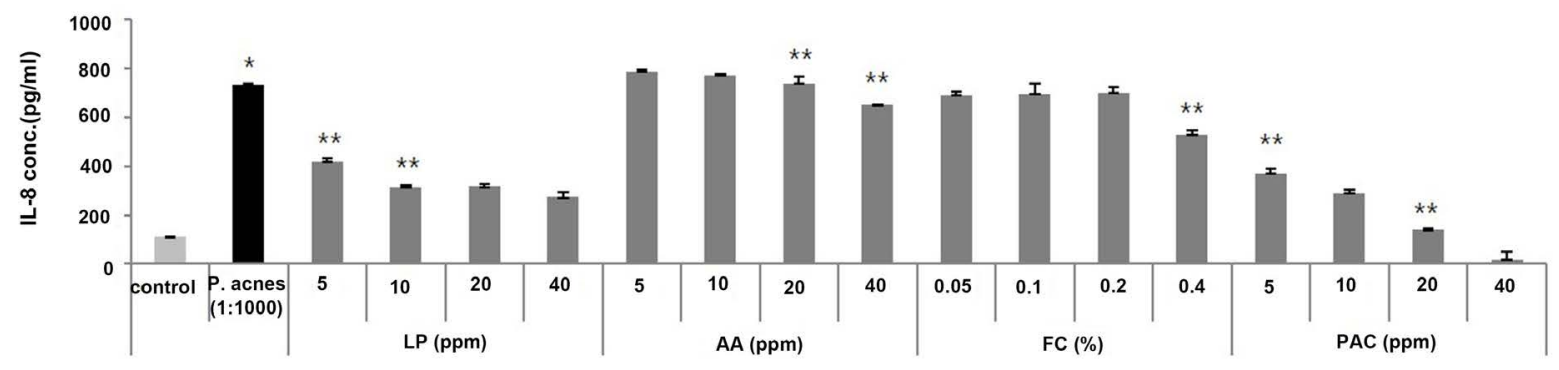

(c)

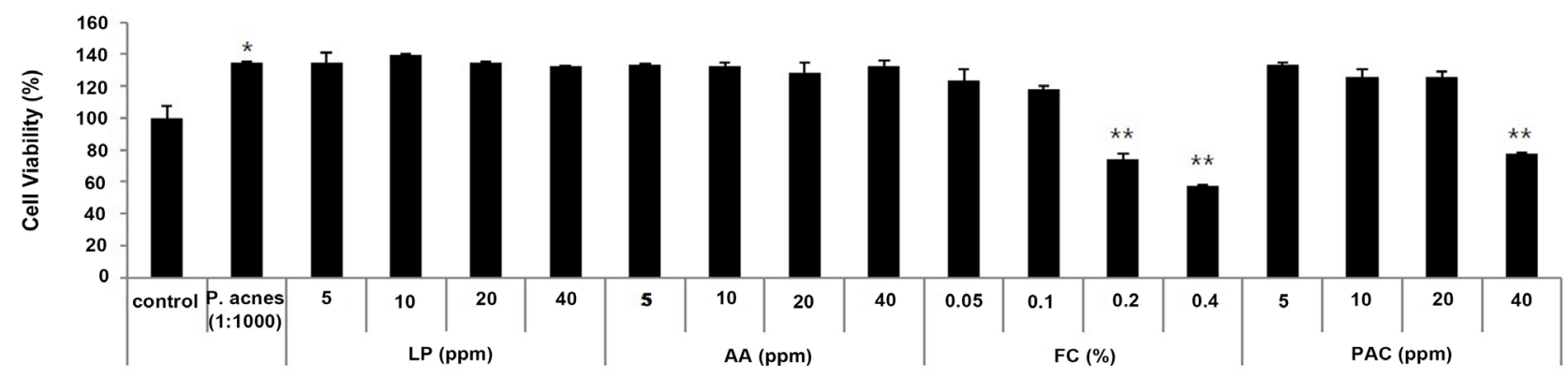

(d)

Figure 1. Inhibitory effects of LP, AA, FC, and PAC on IL-8 production in NF cells and HaCaT cells under $P$. acnes-stimulated inflammation. (a) NF cells were pretreated with the indicated concentration of LP, AA, FC, and PAC for $1 \mathrm{~h}$ and were then further incubated with $P$. acnes (1:1000) for $48 \mathrm{~h}$. The amount of IL-8 secretion was then estimated using an Elisa assay; (b) The cell viability was measured using an MTT assay; (c) After the treatment of LP, AA, FC, and PAC for $1 \mathrm{~h}$, HaCaT cells were further incubated with $P$. acnes (1:1000) for $24 \mathrm{~h}$; (d) The cell viability was analyzed using an MTT assay. The results are presented as mean \pm standard deviation $(\mathrm{SD})(\mathrm{n}=3) .{ }^{\star} \mathrm{P}<0.05$ vs. control. ${ }^{\star *} \mathrm{P}<0.05$ vs. $P$. acnes-stimulated, extract nontreated group.

After the sebocytes were treated with $20 \mathrm{nM}$ of IGF-1, PAC of $1 \mathrm{ug} / \mathrm{ml}$ was treated for $24 \mathrm{~h}$, and the harvested cells were analyzed by the cell cycle analysis. As shown in Figure 4(a), the result indicates that PAC (67.87\%) decreases the 


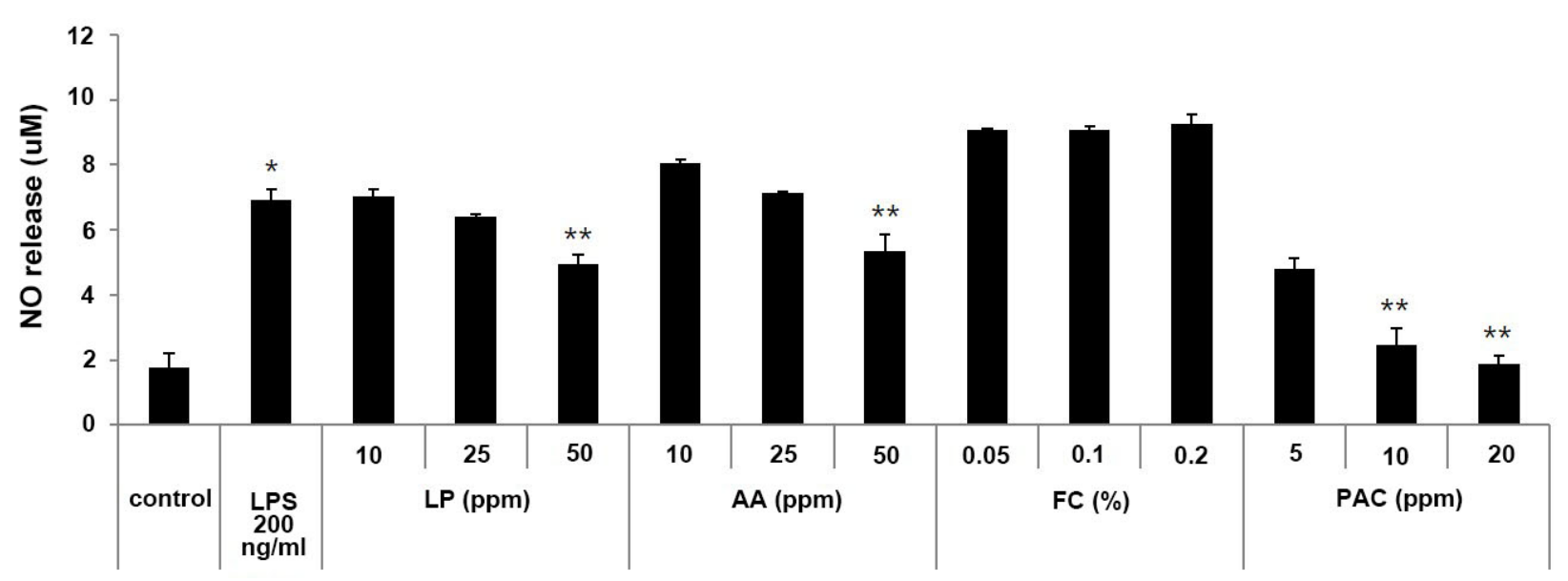

(a)

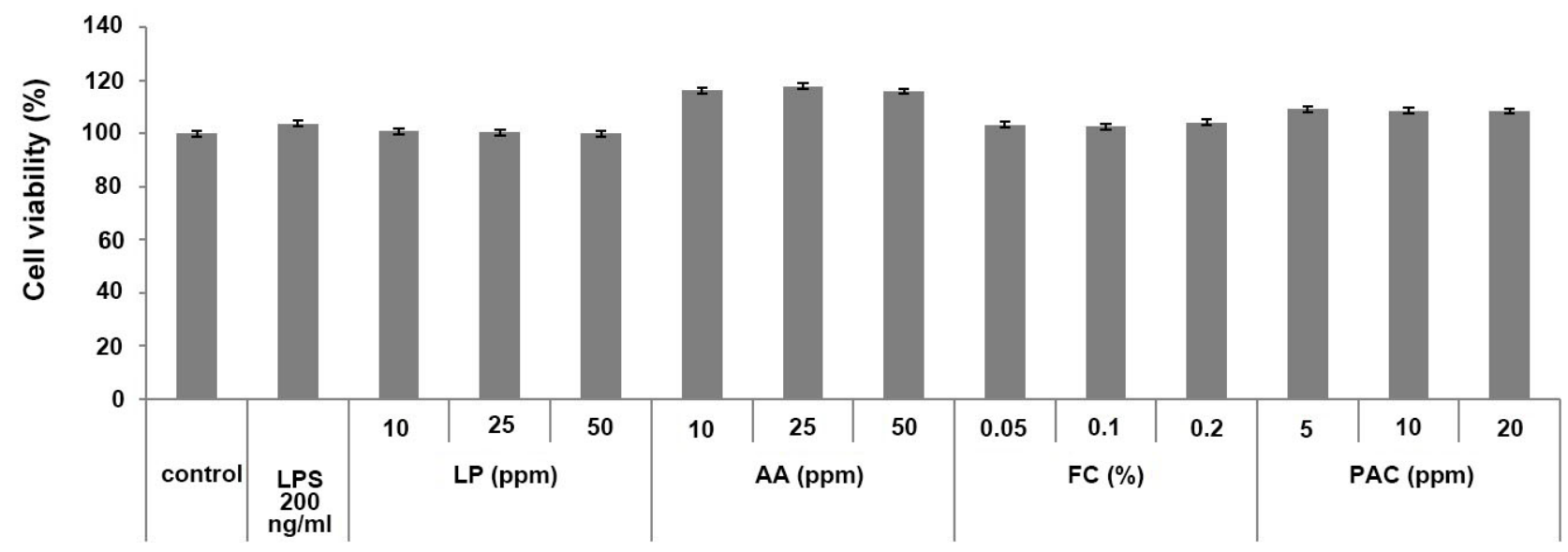

(b)

Figure 2. Inhibitory effects of LP, AA, FC, and PAC on NO release in Raw 264.7 cells on LPS-induced inflammation. (a) The cells were pretreated with the indicated concentration of LP, AA, FC, and PAC for $1 \mathrm{~h}$ and were further incubated with LPS (200 $\mathrm{ng} / \mathrm{ml}$ ) for $24 \mathrm{~h}$. The amount of NO production was then determined by Griess assay; (b) Cell viability was measured by MTT assay. The results are presented as mean \pm standard deviation $(\mathrm{SD})(\mathrm{n}=3) .{ }^{\star} \mathrm{P}<0.05$ vs. control. ${ }^{\star \star} \mathrm{P}<0.05$ vs. LPS-induced, extract nontreated group.

proliferation of SEB-1 cells by arresting the cell cycle progression of a level comparable with $73.94 \%$ of EGCG, is employed as positive control [24] [25] (Figure 3(a)).

\subsection{Suppressive Effect of PAC on Sebocyte Lipogenesis}

An excess in sebum secretion is one of multiple factors that are associated with the pathogenesis of acne and regulating lipid production on sebocytes also has a crucial role in acne treatment. Therefore, PAC was examined to determine whether it has an effect on the lipogenesis of sebocytes upon IGF-1-induced sebum secretion with EGCG as a positive control. Treatment with IGF-1 resulted in an increase in sebum secretion, which was suppressed by treatment with PAC, as observed with nile red staining (Figure $3(\mathrm{~b})$ ). The results suggest that PAC can reduce the rate of sebum excretion stimulated by IGF-1 and can regulate sebum production in acne lesions. 


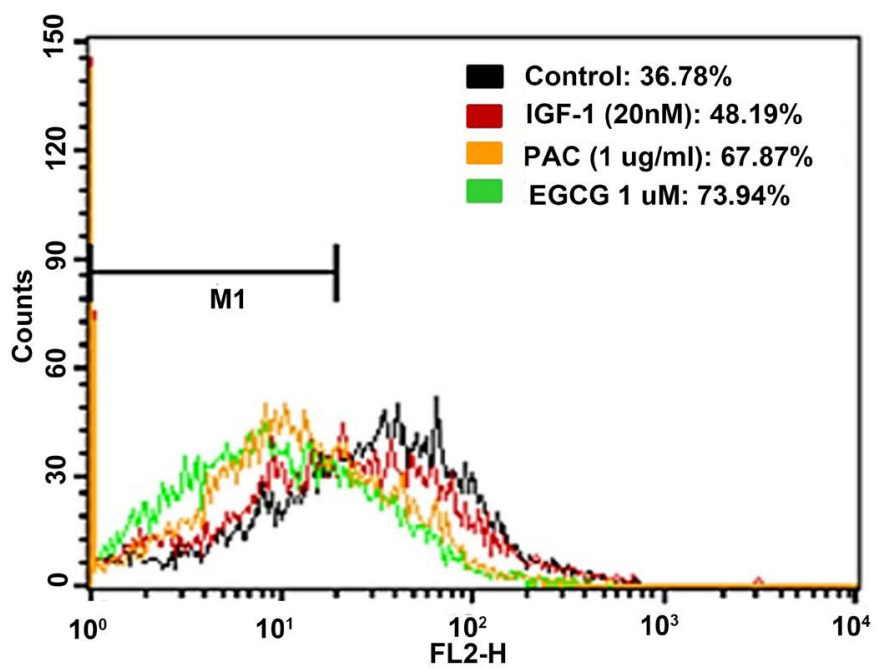

(a)
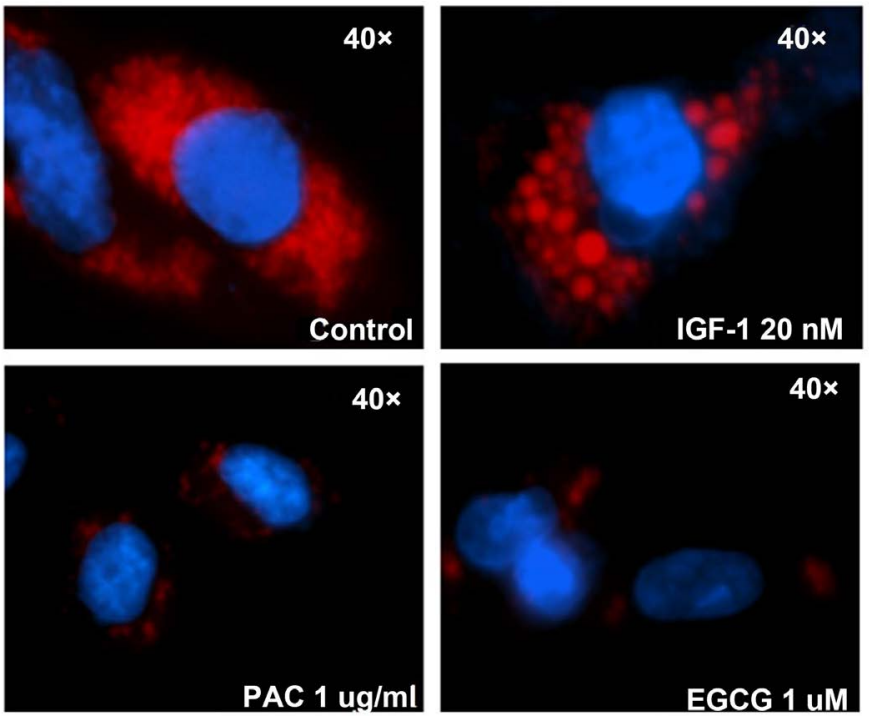

(b)

Figure 3. Suppressive effect of PAC on proliferation and lipogenesis in IGF-1-stimulated SEB-1 sebocytes. (a) Cell cycle progression in SEB-1 sebocytes was analyzed by flow cytometry. Marker 1 (M1) represents apoptotic cells; (b) SEB-1 sebocytes were treated with 20 $\mathrm{nM}$ of IGF-1 with $1 \mathrm{ug} / \mathrm{ml}$ PAC or $1 \mathrm{uM} \mathrm{EGCG} \mathrm{treatments} \mathrm{for} 24 \mathrm{~h}$. Nile red staining was performed to detect lipid (Sebum) production of SEB-1 sebocytes.

\subsection{Clinical Effect of PAC-Containg Test Product on Acne Prone Skin}

To investigate the efficacy of PAC-containing test product versus a control product, the test and control product were applied twice a day for a 4-weeks on 20 volunteers. The skin oil content $(\mu \mathrm{g} / \mathrm{ml})$, number of skin sebum, numbers of non-inflammatory and inflammatory acne lesion was measured before treatment, at 2 weeks and 4 weeks following 4 consecutive weeks treatment of test product. The results showed a significant decrease in skin oil content of $48.9 \%$ 


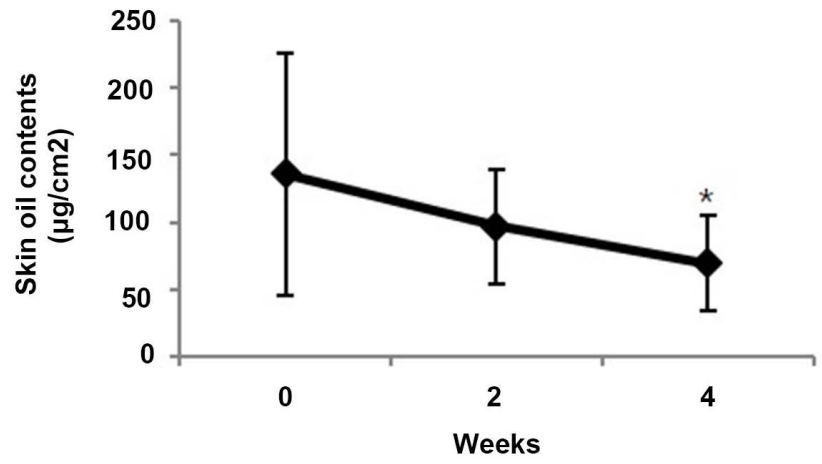

(a)

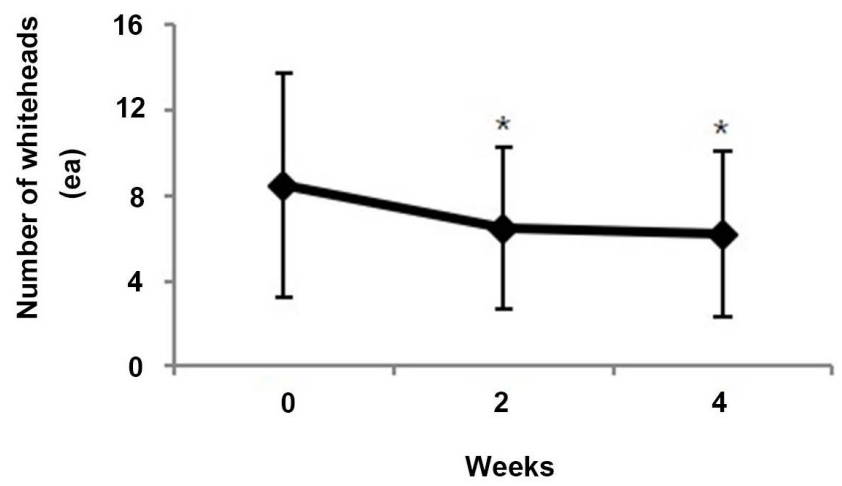

(c)

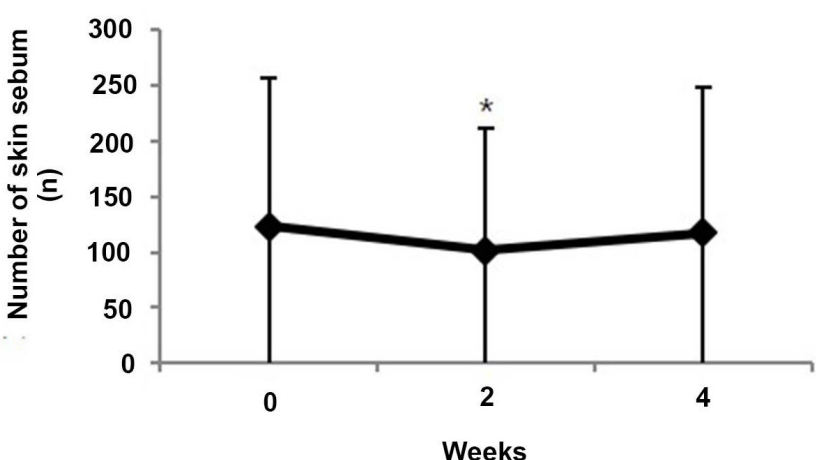

(b)

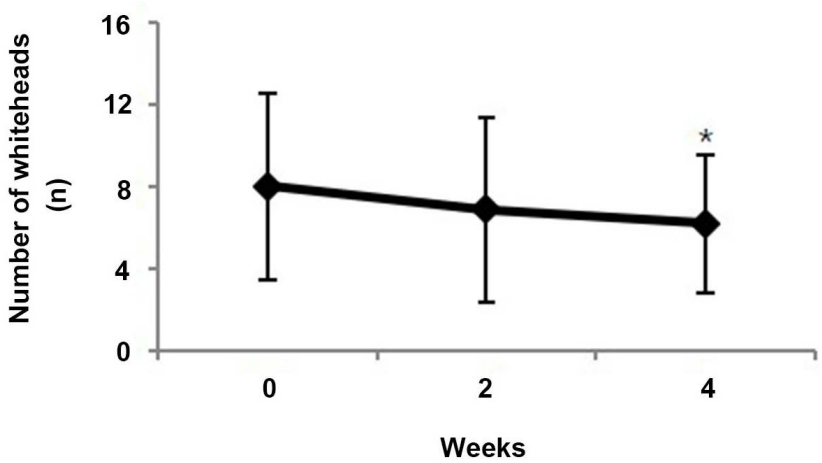

(d)

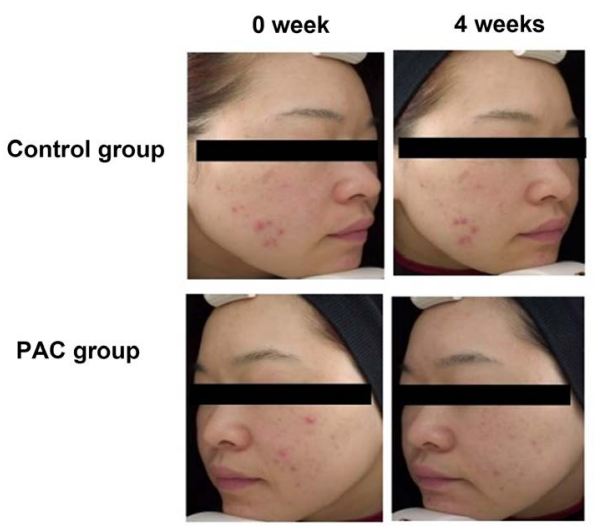

(e)

Figure 4. Effect of Figure 4. Effects of application of PAC-containing test product on acne lesions in a 4-weeks human clinical study. Skin oil content (a); Number of skin sebum (b); Number of whiteheads (c); Number of blackheads (d); and photographs of the faces of control product group (control group) and PAC-containing test product group (PAC group) (e). ${ }^{\star} \mathrm{P}<0.05$ compared with before treatment.

after 4 weeks and sebum secretion rate of $17.6 \%$ after 2 weeks (Figure 4(a), Figure 4(b)). Compared to before treatment, the number of whiteheads and blackheads were significantly reduced at PAC-containg test product group at 2 weeks and 4 weeks (Figure 4(c), Figure 4(d)). In addition, compared to the control product group at 4 weeks, PAC-containg test product group significant reduction of $27.2 \%$ and $11.3 \%$ in the mean number of whiteheads and blackheads. Papules and pustules were showed a tendency to decrease at 4 weeks in 
PAC-containing test product group compared to the control product group (Table 3). These results indicate that the PAC complex exerts an acne-mitigating effect.

\subsection{Human Skin Primary Irritation Test of PAC}

A skin primary irritation test in humans was conducted to evaluate the irritation potential of PAC on human skin. A human patch test is a general method that is used to determine the human skin safety of a substance for clinical applications. The patch test was usually removed after 48 hours, and readings were recorded 30 minutes after removing the strips (day 2) and after 24 (day 3) or 48 (day 4) hours, as modified by Frosch \& Kligman [44]. 31 healthy volunteers aged 20 to 50 years (average $41.6 \pm 6.5 \mathrm{yrs}$ ) were recruited for this study. During this study, none of the 31 subjects experienced a reaction based on the 48- and 72-h readings (Table 4) and PAC did not induce any skin reaction. Therefore, these data demonstrate that the PAC is within the scope of the slight-irritation and is safe to apply to human skin.

\section{Discussions}

Acne is characterized by multifactorial conditions, including hormonal imbalance, abnormal ductal keratinization, bacterial overgrowth, inflammation, and excessive sebum production. Despite the existence of many studies on the pathophysiological mechanisms of acne, the development of effective ingredients for treatment has been limited because such substances have shown a single effect among multiple physiological factors of acne, not on multiple aspects [47] [48]. Recently, there has been an increasing focus on developing therapeutic agents that target multiple pathogenesis of acne, with no side effects. Pretsch et al. reported that Talaromyces wortmannii extracts have an anti-microbial activity against acne-inducing bacteria including $P$. acnes and anti-inflammatory properties by inhibiting $P$. acnes-mediated activation of NF-kB and activator protein-1 (AP-1) activation, as well as IL-8 release [49]. Results from in vitro, ex vivo, and clinical studies on BGM complex composed of bakuchiol, Ginkgo biloba extract, mannitol for acne therapy showed antibacterial activity against

Table 3. Statistical analysis of whiteheads, blackheads, papule and pustule by lesion counting.

\begin{tabular}{cccccc}
\hline Lesion & Weeks & Group & Mean & P-value & Decreation (\%) \\
\hline \multirow{2}{*}{ Whiteheads } & \multirow{2}{*}{$4 \mathrm{~W}$} & Con & 8.50 & $0.005^{*}$ & 27.2 \\
& & PAC & 6.15 & & \\
\multirow{3}{*}{ Blackheads } & \multirow{2}{*}{4} & Con & 7.05 & $0.003^{*}$ & 11.3 \\
& & PAC & 6.20 & & \\
Papules & \multirow{2}{*}{$4 \mathrm{~W}$} & Con & 2.13 & $0.123^{*}$ & 14.1 \\
& & PAC & 1.83 & & \multirow{2}{*}{ Pustules } \\
& $4 \mathrm{~W}$ & Con & 0.55 & $0.614^{*}$ & 9.1 \\
\hline
\end{tabular}

*Significantly different at $\mathrm{P}<0.05$ compared with control group. 
Table 4. Human skin primary irritation test.

\begin{tabular}{|c|c|c|c|c|c|c|c|c|c|c|c|c|c|c|}
\hline \multirow{2}{*}{ No. } & \multirow{2}{*}{$\begin{array}{c}\text { Test } \\
\text { material }\end{array}$} & \multicolumn{3}{|c|}{$48 \mathrm{~h}$} & \multicolumn{7}{|c|}{$72 \mathrm{~h}$} & \multicolumn{3}{|c|}{ Reaction grade } \\
\hline & & \pm & $1+$ & $2+$ & $3+$ & $4+$ & \pm & $1+$ & $2+$ & $3+$ & $4+$ & $48 \mathrm{~h}$ & $72 \mathrm{~h}$ & Mean \\
\hline 1 & Squalene & - & - & - & - & - & - & - & - & - & - & 0 & 0 & 0 \\
\hline 2 & $\operatorname{PAC}(2 \%)$ & - & - & - & - & - & - & - & - & - & - & 0 & 0 & 0 \\
\hline
\end{tabular}

$P$. acne, antioxidation activity of squalene, anti-inflammatory activity and regulation of sebum composition [50].

In the current study, we first report on the antibacterial activity against $P$. acnes of Pinus thunbergii needle extract, Artemisia annua L. extract, and Citrus junos Tanaka fruit juice and anti-inflammatory activity of Pinus thunbergii needles extract and Artemisia annua L. extract.

We also assessed antibacterial properties against $P$. acnes and $S$. epidermidis, anti-inflammatory potential of a new combined plant extract (PAC), consisting of Pinus thunbergii needle extract, Artemisia annua L. extract, and Citrus junos Tanaka fruit juice. PAC showed the lowest MIC value of $2.25 \mathrm{mg} / \mathrm{ml}$ and 0.75 $\mathrm{mg} / \mathrm{ml}$ against $P$. acnes and $S$. epidermidis and was more effective than LP and AA on inhibition of $P$. acnes- and LPS-stimulated inflammation. In addition, we evaluated sebosupressive and clinical effect on acne prone skin of PAC whether PAC can regulate multiple pathogenic factor of acne. The results indicated that PAC had suppressive effect on differentiation and lipogenesis in IGF-1-stimulated SEB-1 cells. In clinical study, compared to the control product group at 4 weeks, skin oil content, skin sebum number, and the numbers of whiteheads and blackheads in PAC-containg test product group were significantly decreased. Furthermore, a patch test was performed to confirm the safety of PAC, and it did not show any adverse reactions on human skin.

Based on these results, this study suggests that PAC may be introduced as a potential therapeutic agent for acne vulgaris.

\section{Conclusion}

In summary, our results reveal that PAC is effective in suppressing multifactorial pathological conditions of acne, including antimicrobial activities against and $S$. epidermidis, anti-inflammatory activities, sebo-suppressive effects, and reduction of skin oil content, sebum number, and the numbers of acne lesions. Therefore, this study demonstrated that the PAC can improve acne treatment and can be provided as an effective new agent for acne therapy.

\section{Acknowledgements}

This research was supported by the Ministry of Trade, Industry \& Energy (MOTIE), Korea Institute for Advancement of Technology (KIAT) through the Encouragement Program for The Industries of Economic Cooperation Region.

\section{References}

[1] Whiting, D.A. (1979) Acne. The Western Journal of Medicine, 131, 551-557. 
[2] Zouboulis, C.C., Seltmann, H., Hiroi, N., Chen W., Young, M., Oeff, M., Scherbaum, W.A., Orfanos, C.E., McCann, S.M. and Bornstein, S.R. (2002) Corticotropin-Releasing Hormone: An Autocrine Hormone That Promotes Lipogenesis in Human Sebocytes. Proceedings of the National Academy of Sciences of the United States of America, 99, 7148-7153. https://doi.org/10.1073/pnas.102180999

[3] Haider, A. and Shaw, J.C. (2004) Treatment of Acne Vulgaris. The Journal of the American Medical Association, 292, 726-735.

https://doi.org/10.1001/jama.292.6.726

[4] Toyoda, M. and Morohashi, M. (2001) Pathogenesis of Acne. Medical Electron Microscopy, 34, 29-40. https://doi.org/10.1007/s007950100002

[5] Harper, J.C. and Thiboutot, D.M. (2003) Pathogenesis of Acne: Recent Research Advances. Advances in Dermatology, 19, 1-10.

[6] Thiboutot, D. (2004) Regulation of Human Sebaceous Glands. Journal of Investigative Dermatology, 123, 1-12. https://doi.org/10.1111/j.1523-1747.2004.t01-2-.X

[7] Kim, J., Ochoa, M.T., Krutzik, S.R., Takeuchi, O., Uematsu, S., Legaspi, A.J., Brightbill, H.D., Holland, D., Cunliffe, W.J., Akira, S., Sieling, P.A., Godowski, P.J. and Modlin, R.L. (2002) Activation of Toll-Like Receptor 2 in Acne Triggers Inflammatory Cytokine Responses. Journal of Immunology, 169, 1535-1541. https://doi.org/10.4049/jimmunol.169.3.1535

[8] Jugeau, S., Tenaud, I., Knol, A.C., Jarrousse, V., Quereux, G., Khammari, A. and Dreno, B. (2005) Induction of Toll-Like Receptors by Propionibacterium acnes. British Journal of Dermatology, 153, 1105-1113. https://doi.org/10.1111/j.1365-2133.2005.06933.x

[9] Kurokawa, I., Danby, F.W., Ju, Q., Wang, X., Xiang, L.F., Xia, L., Chen, WC., Nagy, I., Picardo, M., Suh, D.H., Ganceviciene, R., Schagen, S., Tsatsou, F. and Zouboulis C.C. (2009) New Developments in Our Understanding of Acne Pathogenesis and Treatment. Experimental Dermatology, 18, 821-832. https://doi.org/10.1111/j.1600-0625.2009.00890.x

[10] Christos, C., Hristos, C. and Zouboulis, M.D. (2004) Acne and Sebaceous Gland Function. Clinics in Dermatology, 22, 360-366. https://doi.org/10.1016/j.clindermatol.2004.03.004

[11] Cunliffe, W.J. (1989) Acne. Martin Dunitz, London.

[12] Downing, D.T., Stewart, M.E. and Strauss, J.S. (1989) Changes in Sebum Secretion and the Sebaceous Gland. Clinics in Geriatric Medicine, 5, 109-114.

[13] Smith, K.R. and Thiboutot, D.M. (2008) Sebaceous Gland Lipids: Friend or Foe? Journal of Lipid Research, 49, 271-281.

[14] Stewart, M.E. (1992) Sebaceous Glands Lipids. Seminars in Dermatology, 11, 100-105.

[15] Zouboulis, C.C., Jourdan, E. and Picardo, M. (2014) Acne Is an Inflammatory Disease and Alterations of Sebum Composition Initiate Acne Lesions. Journal of the European Academy of Dermatology and Venereology, 28, 527-532. https://doi.org/10.1111/jdv.12298

[16] Fritsh, M., Orfanos, C.E. and Zouboulis, C.C. (2001) Sebocytes Are the Key Regulators of Androgen Homeostasis in Human Skin. Journal of Investigative Dermatolo$g y, 116,793-800$.

[17] Pappas, A. (2009) Epidermal Surface Lipids. Dermatoendocrinology, 1, 72-76. https://doi.org/10.4161/derm.1.2.7811

[18] Rosenfield, R.L., Deplewski, D., Kentsis, A. and Ciletti, N. (1998) Mechanisms of 
Androgen Induction of Sebocyte Differentiation. Dermatology, 196, 43-46. https://doi.org/10.1159/000017864

[19] Degitz, K., Placzek, M., Borelli, C. and Plewig, G. (2007) Pathophysiology of Acne. Journal der Deutschen Dermatologischen Gesellschaft, 5, 316-323. https://doi.org/10.1111/j.1610-0387.2007.06274.x

[20] Deplewski, D. and Rosenfield, R.L. (1999) Growth Hormone and Insulin-Like Growth Factors Have Different Effects on Sebaceous Cell Growth and Differentiation. Endocrinology, 140, 4089-4094. https://doi.org/10.1210/endo.140.9.6957

[21] Cappel, M., Mauger, D. and Thiboutot, D. (2005) Correlation between Serum Levels of Insulin-Like Growth Factor 1, Dehydroepiandrosterone Sulfate, and Dihydrotestosterone and Acne Lesion Count in Adult Women. Archives of Dermatology, 141, 333-338. https://doi.org/10.1001/archderm.141.3.333

[22] Tasli, L., Turgut, S., Kacar, N., Ayada, C., Coban, M., Akcilar, R. and Ergin, S. (2013) Insulin-Like Growth Factor-I Gene Polymorphism in Acne Vulgaris. Journal of the European Academy of Dermatology and Venereology, 27, 254-257. https://doi.org/10.1111/j.1468-3083.2011.04299.x

[23] Im, M., Kim, S.Y., Sohn, K.C., Choi, D.K., Lee, Y., Seo, Y.J., Kim, C.D., Hwang, Y.L., Zouboulis, C.C. and Lee, J.H. (2012) Epigallocatechin-3-Gallate Suppresses IGF-I-Induced Lipogenesis and Cytokine Expression in SZ95 Sebocytes. Journal of Investigative Dermatology, 132, 2700-2708. https://doi.org/10.1038/jid.2012.202

[24] Van Aller, G.S., Carson, J.D., Tang, W., Peng, H., Zhao, L., Copeland, R.A., Tummino, P.J. and Luo, L. (2011) Epigallocatechin Gallate (EGCG), a Major Component of Green Tea, Is a Dual Phosphoinositide-3-kinase/mTOR Inhibitor. Biochemical and Biophysical Research Communications, 406, 194-199. https://doi.org/10.1016/j.bbrc.2011.02.010

[25] Adams, J.C. and Morehart, A.L. (1982) Decline and Death of Pinus spp. in Delaware Caused by Bursaphelenchus xylophilus. Journal of Nematology, 14, 382-385.

[26] Zhu, J., Gonda, Y., Yu, L., Li, F., Yan, Q. and Sun, Y. (2012) Regeneration of a Coastal Pine (Pinus thunbergii Parl.) Forest 11 Years after Thinning, Niigata, Japan. Public Library of Science One, 7, e47593.

[27] Taniguchi, T., Kanzaki, N., Tamai, S., Yamanaka, N. and Futai, K. (2007) Does Ectomycorrhizal Fungal Community Structure Vary along a Japanese Black Pine (Pinus thunbergii) to Black Locust (Robinia pseudoacacia) Gradient? New Phytologist, 173, 322-334.

[28] Won, J.N., Lee, S.Y., Song, D.S. and Poo, H. (2013) Antiviral Activity of the Plant Extracts from Thuja orientalis, Aster spathulifolius, and Pinus thunbergii against Influenza Virus A/PR/8/34. Journal of Microbiology and Biotechnology, 23, 125-130. https://doi.org/10.4014/jmb.1210.10074

[29] Hong, S.S., Jeong, W., Kim, J.K., Kwon, J.G., Lee, J.Y., Ahn, E.K., Oh, J., Seo, D.W. and Oh, J.S. (2014) Neolignan Inhibitors of Antigen-Induced Degranulation in RBL-2H3 Cells from the Needles of Pinus thunbergii. Fitoterapia, 99, 347-351. https://doi.org/10.1016/j.fitote.2014.10.015

[30] Deng, Y., Liu, Z. and Geng, Y. (2016) Anti-Allergic Effect Artemisia Extract in Rats. Experimental and Therapeutic Medicine, 12, 1130-1134. https://doi.org/10.3892/etm.2016.3361

[31] Mueller, M.S., Runyambo, N., Wagner, I., Borrmann, S., Dietz, K. and Heide, L. (2004) Randomized Controlled Trial of a Traditional Preparation of Artemisia annua L. (Annual Wormwood) in the Treatment of Malaria. Transactions of the Royal Society of Tropical Medicine and Hygiene, 98, 318-321. 
https://doi.org/10.1016/j.trstmh.2003.09.001

[32] Klayman, D.L. (1985) Qinghaosu (Artemisinin): An Antimalarial Drug from China. Science, 228, 1049-1055. https://doi.org/10.1126/science.3887571

[33] Zhao, Y.G., Wang, Y., Guo, Z., Gu, A.D., Dan, H.C., Baldwin, A.S., Hao, W. and Wan, Y.Y. (2012) Dihydroartemisinin Ameliorates Inflammatory Disease by Its Reciprocal Effects on Th and Regulatory T Cell Function via Modulating the Mammalian Target of Rapamycin Pathway. The Journal of Immunology, 189, 4417-4425. https://doi.org/10.4049/jimmunol.1200919

[34] Radulović, N.S., Randjelović, P.J., Stojanović, N.M., Blagojević, P.D., Stojanović-Radić, Z.Z., Ilić, I.R. and Djordjević, V.B. (2013) Toxic Essential Oils. Part II: Chemical, Toxicological, Pharmacological and Microbiological Profiles of Artemisia annua L. Volatiles. Food and Chemical Toxicology, 58, 37-49. https://doi.org/10.1016/j.fct.2013.04.016

[35] Wu, X., Zhang, W., Shi, X., An, P., Sun, W. and Wang, Z. (2010) Therapeutic Effect of Artemisinin on Lupus Nephritis Mice and Its Mechanisms. Acta Biochimica et Biophysica Sinica (Shanghai), 42, 916-923. https://doi.org/10.1093/abbs/gmq101

[36] Bamunuarachchi, G.S., Ratnasooriya, W.D., Premakumara, S. and Udagama, P.V. (2013) Antimalarial Properties of Artemisia vulgaris L. Ethanolic Leaf Extract in a Plasmodium berghei Murine Malaria Model. Journal of Vector Borne Diseases, 50 , 278-284.

[37] Yoo, K.M., Lee, K.W., Park, J.B., Lee, H.J. and Hwang, I.K. (2004) Variation in Major Antioxidants and Total Antioxidant Activity of Yuzu (Citrus junos Sieb ex Tanaka) during Maturation and between Cultivars. Journal of Agricultural and Food Chemistry, 2, 5907-5913. https://doi.org/10.1021/jf0498158

[38] Sawamura, M., Wu, Y., Fujiwara, C. and Urushibata, M. (2005) Inhibitory Effect of Yuzu Essential Oil on the Formation of N-Nitrosodimethylamine in Vegetables. Journal of Agricultural and Food Chemistry, 53, 4281-4287. https://doi.org/10.1021/jf047816u

[39] Kim, S.H., Hur, H.J., Yang, H.J., Kim, H.J., Kim, M.J., Park, J.H., Sung, M.J., Kim, M.S., Kwon, D.Y. and Hwang, J.T. (2013) Citrus junos Tanaka Peel Extract Exerts Antidiabetic Effects via AMPK and PPAR- $\gamma$ both In Vitro and In Vivo in Mice Fed a High-Fat Diet. Evidence-Based Complementary and Alternative Medicine, 2013, Article ID: 921012.

[40] Shin, E.J., Park, J.H., Sung, M.J., Chung, M.Y. and Hwang, J.T. (2016) Citrus junos Tanaka Peel Ameliorates Hepatic Lipid Accumulation in HepG2 Cells and in Mice Fed a High-Cholesterol Diet. BMC Complementary and Alternative Medicine, 16, 499. https://doi.org/10.1186/s12906-016-1460-y

[41] Konno, N. (2009) Mental Caring for Pre-Symptomatic Depression by Aroma-Effects of Lemon and Yuzu Essential Oil. Aroma Research, 39, 260-263.

[42] Green, L.C., Wagner, D.A., Glogowski, J., Skipper, P.L., Wishnok, J.S. and Tannenbaum, S.R. (1982) Analysis of Nitrate, Nitrite, and [15N] Nitrate in Biological Fluids. Analytical Biochemistry, 126, 131-138. https://doi.org/10.1016/0003-2697(82)90118-X

[43] Frosch, P.J. and Kligman, A.M. (1979) The Soap Chamber Test. A New Method for Assessing the Irritancy of Soaps. Journal of the American Academy of Dermatology, 1, 35-41. https://doi.org/10.1016/S0190-9622(79)70001-6

[44] Graham, G.M., Farrar, M.D., Cruse-Sawyer, J.E., Holland, K.T. and Ingham, E. (2004) Proinflammatory Cytokine Production by Human Keratinocytes Stimulated with Propionibacterium acnes and GroEL. British Journal of Dermatology, 150, 
421-428.

[45] Nagy, I., Pivarcsi, A., Kis, K., Koreck, A., Bodai, L., McDowell, A., Seltmann, H., Patrick, S., Zouboulis, C.C. and Kemény, L. (2006) Propionibacterium acnes and Lipopolysaccharide Induce the Expression of Antimicrobial Peptides and Proinflammatory Cytokines/Chemokines in Human Sebocytes. Microbes and Infection, 8, 2195-2205. https://doi.org/10.1016/j.micinf.2006.04.001

[46] Guin, J.D., Huber, D.S. and Gielerak, P.L. (1979) Antibiotic Sensitivity of Comedonal Propionibacterium acnes. Acta Dermato- Venereologica, 59, 552-554.

[47] Jappe, U. (2003) Pathological Mechanisms of Acne with Special Emphasis on Propionibacterium acnes and Related Therapy. Acta Dermato-Venereologica, 83, 241-248. https://doi.org/10.1080/00015550310016463

[48] Pretsch, A., Nagl, M., Schwendinger, K., Kreiseder, B., Wiederstein, M., Pretsch, D., Genov, M., Hollaus, R., Zinssmeister, D., Debbab, A., Hundsberger, H., Eger, A., Proksch, P. and Wiesner, C. (2014) Antimicrobial and Anti-Inflammatory Activities of Endophytic Fungi Talaromyces wortmannii Extracts against Acne-Inducing Bacteria. Public Library of Science One, 9, e97929.

https://doi.org/10.1371/journal.pone.0097929

[49] Trompezinski, S., Weber, S., Cadars, B., Larue, F., Ardiet, N., Chavagnac-Bonneville, M., Sayag, M. and Jourdan, E. (2016) Assessment of a New Biological Complex Efficacy on Dysseborrhea, Inflammation, and Propionibacterium acnes Proliferation. Clinical, Cosmetic and Investigational Dermatology, 9, 233-239. https://doi.org/10.2147/CCID.S110655

[50] Yoon, J.Y., Kwon, H.H., Min, S.U., Thiboutot, D.M. and Suh, D.H. (2013) Epigallocatechin-3-Gallate Improves Acne in Humans by Modulating Intracellular Molecular Targets and Inhibiting P. acnes. Journal of Investigative Dermatology, 133, 429-440. https://doi.org/10.1038/jid.2012.292 